\title{
Clinical pattern and presentation of abnormal uterine bleeding
}

\author{
Sarala V., Ushadevi Gopalan*
}

Department of Obstetrics and Gynecology, Shri Sathya Sai Medical College and Research Institute, Ammapettai, Kancheepuram, Tamil Nadu, India

Received: 11 November 2019

Revised: 30 November 2019

Accepted: 02 December 2019

\section{*Correspondence:}

Dr. Ushadevi Gopalan,

E-mail: ushag7@hotmail.com

Copyright: (C) the author(s), publisher and licensee Medip Academy. This is an open-access article distributed under the terms of the Creative Commons Attribution Non-Commercial License, which permits unrestricted non-commercial use, distribution, and reproduction in any medium, provided the original work is properly cited.

\begin{abstract}
Background: Abnormal uterine bleeding (AUB) is a very common debilitating gynecological condition among women of the reproductive age group. This diagnosis is given to women in whom no clear etiology is identified. It can occur in ovulatory and anovulatory cycle. It influences the physical, emotional, sexual and professional life of a woman. This study was carried out to evaluate the clinical profile of abnormal uterine bleeding.

Methods: This cross-sectional study was carried out among 350 patients who were clinically diagnosed with AUB for a period of one year from April 2018 to March 2019. Patients with uterine polyp, adenomyosis, Leiomyoma, malignancies and with various coagulopathies were excluded from the study by physical examination, ultrasound, histopathology and blood test. The remaining 280 patients between the ages 20-60 years were selected for clinical classification of AUB.

Results: Majority of the participants were in the age group of 41-50 years (60\%). AUB is most commonly seen in multiparous women (48.92\%). The prominent bleeding pattern seen was menorrhagia (52.2\%).

Conclusions: Menorrhagia is the most common form of AUB and there is a need to prevent the consequences of menorrhagia by way of creating awareness among the women, and by early diagnosis and clinical management of complications.
\end{abstract}

Keywords: Anovulation, Menorrhagia, Polymenorrhoea, Uterine bleeding

\section{INTRODUCTION}

Abnormal uterine bleeding (AUB) is the most common clinical presentation in gynecology outpatient clinics throughout the world. It is present in $9-14 \%$ of women between menarche and menopause, which is the reproductive age group. ${ }^{1}$ In general terms, AUB signifies changes in the duration and frequency of menstruation and the amount of blood loss. Although AUB may be characterized by specific menstrual abnormalities including dysmenorrhea, menorrhagia, oligomenorrhea, etc., the cause of AUB is often unknown. According to International Federation of Obstetrics and Gynecology (FIGO) the classification of AUB is based on PALM-
COEIN which is an acronym for various etiologies namely polyp, adenomyosis, leiomyoma, malignancy and hyperplasia, coagulopathy, ovulatory dysfunction, endometrial disorders, iatrogenic and not otherwise classified (PALM-COEIN). ${ }^{2}$

At the pathological level, AUB is predominantly characterized by anovulatory cycles. When ovulation does not occur, no corpus luteum is formed to produce progesterone, leading to prolonged estrogenic stimulation of the endometrium and irregular bleeding. The patient will present with polymennorrhagia, polymenorrhea and metrorrhagia. The non-shedding of endometrium causes an increased risk of endometrial cancer. As a clinical 
approach to AUB, it is essential to obtain history pertaining to puberty and menstrual history in terms of regularity, volume and duration of cycles. In addition, reproductive and sexual history plays a major role in determining the etiology of AUB in married women. It is also essential to consider various non-reproductive causes of AUB, namely nutritional history, endocrine disorders, socioeconomic status and current medication history.

Clinical evaluation in terms of abdominal and per vaginal examination aids in the diagnosis. But conclusive results are obtained only when the endometrium is examined either by ultrasound or histological sampling. ${ }^{3}$

In majority of the patients, AUB is a recurring problem and therefore, poses a challenge to the care providers in terms of clinical management. Moreover, its consequences are increasingly incriminating on the quality of life of these reproductive women, due to the impact on general health and wellbeing. Although studies have been done on evaluating the endometrium for various pathologies, there is still a vacuum with regards to the clinical presentation and correlation of AUB. Clinical correlation plays a significant role in limited resource settings, especially in developing economies like India, and an in-depth evaluation of clinical presentation of AUB will aid the primary care physician to detect AUB at an early stage and appropriate referral for advanced care.

\section{METHODS}

This cross-sectional study was carried out in the department of obstetrics and gynecology of our tertiary teaching institution for a period of one year between April 2018 and March 2019. All the adult women in the reproductive age group who were clinically diagnosed with AUB were taken up for the study.

\section{Sample size and sampling technique}

Based on intensive literature review, the lowest prevalence of AUB was observed with metrorrhagia in a study done by Kansal Y et al, which was $2.1 \%$ At $95 \%$ confidence limits and $1.75 \%$ absolute precision, the sample size was calculated as $258 .{ }^{4}$ Accounting $10 \%$ for non-response, the sample size was recalculated as 282 and was rounded off to 280 .

A total of 350 participants visited the outpatient department during the study period with clinical symptoms suggestive of AUB. Among them, 70 participants were excluded due to various structural pathologies like polyps, Adenomyosis, etc by ultrasound examination and histopathology. The required sample of 280 participants were selected using convenience sampling

Approval was obtained from the Institutional Ethics Committee prior to the commencement of the study. Each participant was explained in detail about the study and written informed consent was obtained prior to the data collection.

\section{Data collection}

A structured interview schedule was used to obtain information regarding the background characteristics, reproductive and menstrual history among the study participants. The data obtained was reclassified to various types of menstrual irregularities among the study participants.

\section{Statistical analysis}

Data was entered and analyzed using Microsoft Excel spreadsheet. The prevalence of various types of AUB was expressed in terms of percentages.

\section{RESULTS}

This study was carried out among 280 participants who presented with clinical features of AUB to the outpatient department of obstetrics and gynecology in our tertiary care teaching institution. The study was done for a period of one year from April 2018 to March 2019. In our study, the youngest age of women diagnosed with AUB was 21 years and the oldest was 60 years. Majority of the participants belonged to the age group of 41-50 years (60\%) (Table 1).

Table 1: Age group.

\begin{tabular}{|lll|}
\hline $\begin{array}{l}\text { Age group } \\
\text { (in years) }\end{array}$ & $\begin{array}{l}\text { Frequency } \\
(\mathbf{N}=280)\end{array}$ & $\begin{array}{l}\text { Percentage } \\
(\%)\end{array}$ \\
\hline $21-30$ & 16 & 5.7 \\
\hline $31-40$ & 84 & 30 \\
\hline $41-50$ & 168 & 60 \\
\hline $51-60$ & 12 & 4.3 \\
\hline
\end{tabular}

Table 2: Parity.

\begin{tabular}{|lll|}
\hline Parity & $\begin{array}{l}\text { Frequency } \\
(\mathbf{N}=\mathbf{2 8 0})\end{array}$ & $\begin{array}{l}\text { Percentage } \\
(\boldsymbol{\%})\end{array}$ \\
\hline Nulliparity & 3 & 1.07 \\
\hline Parity 1 & 56 & 20 \\
\hline Parity 2 & 137 & 48.93 \\
\hline Parity 3 & 84 & 30 \\
\hline
\end{tabular}

Table 3: Socio economic status.

\begin{tabular}{|lll|}
\hline $\begin{array}{l}\text { Socioeconomic } \\
\text { status }\end{array}$ & $\begin{array}{l}\text { Frequency } \\
(\mathbf{N}=\mathbf{2 8 0})\end{array}$ & $\begin{array}{l}\text { Percentage } \\
(\%)\end{array}$ \\
\hline Lower group & 196 & 70 \\
\hline Higher group & 84 & 30 \\
\hline
\end{tabular}

As regarding parity, most of the women with DUB were multiparous $(48.9 \%)$ with least in nulliparous women $(1.07 \%)$ (Table 2). In our study, majority of the participants belonged to lower socioeconomic status (70\%) (Table 3). Among the various categories of AUB, 
menorrhagia was the most predominant type $(52.2 \%)$ followed by polymenorrhagia $(21.1 \%)$ and least was postmenopausal bleeding (2.25\%) (Table 4).

Table 4: Various bleeding pattern.

\begin{tabular}{|lll|}
\hline Type of bleeding & $\begin{array}{l}\text { Frequency } \\
(\mathbf{N}=\mathbf{2 8 0})\end{array}$ & $\begin{array}{l}\text { Percentage } \\
(\%)\end{array}$ \\
\hline Menorrhagia & 146 & 52.2 \\
\hline Polymenorrhagia & 59 & 21.1 \\
\hline Polymenorrhea & 45 & 16 \\
\hline Metrorrhagia & 22 & 7.85 \\
\hline Post-menopausal bleeding & 8 & 2.85 \\
\hline
\end{tabular}

\section{DISCUSSION}

The management of abnormal uterine bleeding (AUB) is based upon clinical diagnosis, complemented with radiological and histopathological confirmation. Therefore, clinical approach to case management is highly integral and used as a definitive guide. In our study, the majority of the participants were aged between 41-50 years which is almost similar to the findings observed by Sujatha R $(60.83 \%) .{ }^{5}$ In another study done by Sinha $\mathrm{K}$ et al, majority of the participants were aged between 40-49 years and menorrhagia was prevalent in $58.45 \%$, similar to our study findings. ${ }^{6}$ In our study menorrhagia was the most common presenting symptom (52.2\%). In a similar study done by Kotagasti et al, menorrhagia was the predominant symptom, seen in $33 \%$ and it was $41.6 \%$ in a study done by Katuwal $\mathrm{N}$ in Nepal. ${ }^{7,8}$ In our study the majority of patients were multiparous (49.93\%), Mahapatra $\mathrm{M}$ et al observed almost similar results of multiparous women $(67.2 \%){ }^{9}$ Our study has elucidated that multiparous women were higher in numbers and were at an increased risk of abnormal uterine bleeding. Although parity has not been implicated as a risk factor, the presence of hormonal variations during the pregnancy has a significant role to play in determining the menstrual pattern after pregnancy. Although data on abnormal uterine bleeding in developing countries is limited, available literature has documented higher prevalence of menorrhagia, and this finding has a direct impact on the nutritional status of the women, and indirect impact on the quality of life. The principal aim of managing AUB is to identify its cause. Based on the FIGO guidelines, it is important to classify the AUB based on ultrasound and histological findings. The treatment of AUB is based on the PALM-COEIN classification of diagnosis of AUB.

However, the mainstay in the management is to provide symptomatic cure and prevention of complications, which includes managing the bleeding episodes, regularization of menstrual cycles and adequate supplementation of iron and folic acid to prevent anemia. It is also essential to work out a differential diagnosis and examine the indications for surgical removal of the uterus, in conditions deemed necessary.

\section{CONCLUSION}

Abnormal uterine bleeding although a common outpatient condition requires in depth evaluation and management. Our study has substantiated the magnitude of menorrhagia which is a debilitating type of AUB warranting immediate attention and management. It is essential to create awareness regarding the risk factors, clinical indications and prevention of AUB among the women and adolescent girls, especially in a developing country like India, so as to enable them to access primary care at the earliest and prevent complications that can easily hamper the quality of life and fertility.

\section{Funding: No funding sources}

Conflict of interest: None declared

Ethical approval: The study was approved by the Institutional Ethics Committee

\section{REFERENCES}

1. Fraser IS, Langham S, Uhl-Hochgraeber. Health related quality of life and economic burden of abnormal uterine bleeding. Expert Rev Obs Gyn. 2009;4(2):179-89.

2. Cheong Y, Cameron IT, Critchley HOD. Abnormal uterine bleeding. Br Med Bull. 2017;123(1):103-14.

3. Davis E, Sparzak PB. Abnormal uterine bleeding (dysfunctional uterine bleeding), 2018. Available at: https://www.ncbi.nlm.nih.gov/books/NBK532913/.

4. Kansal Y, Bahadur A, Chaturvedi J, Rao S, Arora H, Kumari $\mathrm{O}$, et al. Spectrum of abnormal uterine bleeding: clinical pattern and endometrial pathology aspects. J Gynecol Surg. 2018;34(1):12-7.

5. Sujatha R. Study of dysfunctional uterine bleeding in patients in a medical college hospital. Indian $\mathrm{J}$ Obstet Gynecol Res. 2019;6:308-11.

6. Sinha S, Gurung P, Singa HH, Bhadani PP. Study on abnormal uterine bleeding among adult women in a tertiary care hospital in Bihar, India. Int $\mathrm{J}$ Reprod Contracept Obstet Gynecol. 2018;7(8):3136-40.

7. Kotibasti T. Prevalence of different menstrual irregularities in women with abnormal uterine bleeding (AUB) - an observational study. Int J Cur Res Rev. 2015;7(10):66-70.

8. Katuwal N, Gurung G, Rana A, Jha A. A clinicopathological study of dysfunctional uterine bleeding. J Pathol Nepal. 2014;4:635-8.

9. Mahapatra M, Pratima M. Clinicopathological evaluation of abnormal uterine bleeding. J Health Res Rev. 2015;2:45-9.

Cite this article as: Sarala V, Gopalan U. Clinical pattern and presentation of abnormal uterine bleeding. Int J Reprod Contracept Obstet Gynecol 2020;9:126-8. 